\title{
Editorial
}

\section{SEER ou não SEER? Eis a questão}

Que é mais nobre para a alma: suportar os dardos
e arremessos do fado sempre adverso, ou armar-
se contra um mar de desventuras e dar-lhes fim tentando resistir-lhes?

Shakespeare, Hamlet

Contrariamente ao drama existencial shakespeareano do príncipe Hamlet, o destino das revistas científicas já foi traçado, não restando a nós, editores, outro caminho a não ser o de ceder aos encantos da tecnologia da informação, com suas tentadoras promessas de agilidade, presteza e visibilidade. Não bastassem esses qualificativos, o sistema de editoração eletrônica de acesso aberto e livre vem ainda atrelado a uma proposta arrebatadora de democratização da informação científica. Tal engajamento político já foi encampado por reconhecidas entidades como a Associação Nacional de Pesquisa e Pós-graduação em Psicologia - ANPEPP, que, em seu último simpósio ocorrido em maio de 2006 em Florianópolis, produziu um manifesto no intuito de apoiar o movimento mundial da comunidade científica em favor do acesso aberto à literatura de pesquisa qualificada.

Entre as recomendações do manifesto, constam o apoio e endosso ao conceito de publicação científica de acesso aberto; a sugestão de que as entidades de fomento mantenham e ampliem sua política de apoio financeiro aos periódicos brasileiros de acesso aberto, cooperando para a construção de um sistema consolidado e abrangente de periódicos científicos de alto impacto no hemisfério sul; que os pesquisadores priorizem as revistas de acesso aberto quando forem submeter seus originais, aceitar solicitações para revisar artigos ou fazer recomendações; e que a adesão ao acesso aberto seja uma condição mínima para que um periódico receba a classificação de qualidade A no Qualis da Psicologia (ANPEPP, 2006).

Estas determinações já se fazem sentir, por exemplo, nos editais de apoio à editoração e publicação de periódicos científicos do CNPq, cujo objetivo é “Apoiar e incentivar a editoração e publicação de periódicos científicos brasileiros, sendo considerado prioritário o apoio às revistas divulgadas simultaneamente por meio eletrônico na Internet, em modo de acesso aberto, em todas as áreas do conhecimento". (MCT/CNPq, 2006).

Como em quase todo convite à mudança, o temor e a resistência frente a essa novidade se traduzem nas reações dos diversos atores pertencentes ao elenco editorial. Editores, autores e consultores são suscetíveis ao impacto das novas tecnologias e se vêem diante de necessidades de um rápido domínio de habilidades e linguagens, muitas vezes, alheios a seus saberes. Como já vem sendo anunciado em números anteriores da revista Psicologia: Teoria e Pesquisa, faz parte de nossos planos imediatos inaugurar uma nova fase na nossa história de tramitação editorial, o que cronologicamente coincide com a maioridade e maturidade da revista. Em conformidade com nossa missão de manter e aperfeiçoar as práticas editoriais, em breve, a revista Psicologia: Teoria e Pesquisa passará a funcionar com base no modelo operacional do Sistema Eletrônico de Editoração de Revistas (SEER) - traduzido e customizado pelo Instituto Brasileiro de Informação em Ciência e Tecnologia (IBICT), baseado no software desenvolvido pelo Public Knowledge Project (Open Journal Systems) da Universidade British Columbia (IBICT, 2006).

Cumpre ressaltar, contudo, que a iniciativa da Revista Psicologia: Teoria Pesquisa em tomar outros rumos em sua operacionalização editorial coaduna-se com o compromisso em dar continuidade à sua missão de garantir a qualidade da produção e divulgação brasileira e internacional em Psicologia, fornecendo um panorama global da produção teórico-metodológica e técnica atual. Por outro lado, pretende-se fazer uma cuidadosa transição para o novo modelo de gestão editorial, tendo em vista a necessidade de considerar as eventuais dificuldades inerentes ao processo de familiarização com esse novo modo de funcionamento.

Neste número, o leitor poderá apreciar, na área de análise experimental do comportamento, o estudo de Francynete Silva e Luiz Carlos Albuquerque sobre efeitos das perguntas no seguir regras e o estudo sobre as variáveis no ensino de discriminação de bebês de Thais de Oliveira, Maria Giol, Naiara de Sousa e Danilo Faleiros. Na área das neurociências, há o estudo sobre as funções neuropsicológicas em crianças com dificuldades de leitura e escrita de Jerusa de Salles, Maria Alice Parente; o estudo da modelagem da agressão de Sílvio Vasconcellos, Patrícia Picon e Gabriel Gauer e o trabalho sobre peritagem musical e cognição de Afonso Galvão. Na área da psicologia do desenvolvimento, Maria Helena Fávero e Larissa Abrão tratam das questões da manutenção dos papéis de gênero na telenovela, a partir dos atos de fala de adolescentes.

Ana Peuker, Janaína Fogaça e Lisiane Bizarro tratam do estudo sobre os fatores de risco associados ao fenômeno do beber problemático entre universitários. A síndrome psicossocial multidimensional de assédio psicológico no trabalho (mobbing) é tratada por Liliana Guimarães e Adriana Rimoli. A discussão sobre as abordagens multi-metodológicas de pesquisas qualitativas e quantitativas é apresentada no artigo de Hartmut Günther, com interessantes aportes da literatura germânica.

Thémis Apostolidis nos brinda com um artigo em francês sobre as representações sociais e a triangulação, na perspectiva da psicologia social da saúde. $\mathrm{Na}$ área de psicologia da arte, Arley Andriolo aborda a falta de diálogo entre pesquisadores sobre a pintura ingênua nos ateliês psiquiátricos. A psicanálise é discutida no trabalho de Jorge Luís Abrão, que trata sobre o seu papel na transformação das práticas educacionais brasileiras e, por sua vez, Eliana Lazzarini e Terezinha Viana tratam do conceito de corpo em psicanálise. Por fim, uma resenha sobre as contribuições teóricas e práticas da psicologia das habilidades sociais na infância é apresentada por Lucas Freitas. Desejo aos caros leitores, bom proveito da leitura.

Maria Inês Gandolfo Conceição Editora 


\section{I. G. Conceição}

\section{Referências}

ANPEPP (2006). XI Simpósio da ANPEPP. Declaração de Florianópolis em favor do acesso aberto. Disponível em 28/08/06 no http://www.anpepp.org.br

IBICT (2006). Acesso Livre à informação científica. Disponível em 28/08/06 no http://www.ibict.br/openaccess/

MCT/CNPq (2006). Edital MCT/CNPq no36/2006. Disponível em 28/08/06 no http://www.cnpq.br/editais/index.htm\#b
Shakespeare, W. (1603). The Tragicall Hiftorie of Hamlet Prince of Denmarke. A Tragédia de Hamlet, Príncipe da Dinamarca. Disponível em 28/08/06 no http://www.2dmais.com.br/livros/ WilliamShakespeare/hamlet 1.pdf\#search $=\% 22$ livrosGratis $\% 2$ FHamlet.htm\%22 